\title{
Código X em Casa: um relato de experiência sobre o ensino remoto de computação desplugada para meninas em situação de vulnerabilidade socioeconômica, em tempos de distanciamento social
}

\author{
Letícia A. de Figueiredo ${ }^{1}$, Ana Beatriz A. Dias ${ }^{2}$, Laryssa A. G. Fagundes ${ }^{1}$, \\ Viviane de P. Silva ${ }^{2}$, Sílvia G. M. Almeida ${ }^{2}$, Mariane L. C. Magalhães ${ }^{1}$, \\ Pâmela M. Rezende ${ }^{3,4}$, Marina O. Lima ${ }^{1}$, Laís S. Fortes ${ }^{5}$, Olívia S. Resende ${ }^{6}$, \\ Pâmela S. B. Gomes ${ }^{2}$, Joicymara S. Xavier ${ }^{3,7}$ \\ ${ }^{1}$ Universidade Federal de Ouro Preto, ${ }^{2}$ IFMG Campus Ouro Preto, \\ ${ }^{3}$ Universidade Federal de Minas Gerais, ${ }^{4}$ Stilingue Inteligência Artificial, \\ ${ }^{5}$ VLI Multimodal S.A, ${ }^{6}$ DTI Digital, \\ ${ }^{7}$ Universidade Federal dos Vales do Jequitinhonha e Mucuri \\ codigox.ong@gmail.com
}

\begin{abstract}
In face of the evident gender inequality, mainly in areas related to technology, Código X project seeks to give girls, who attended elementary school and live in regions of social vulnerability, a contact with activities outside their reality. During the period of social isolation, new challenges arise to minimize inequalities, stimulating the development of new methodologies. Thus Código $X$ em casa was born, creating a way of remote teaching of logic and programming. The methodology is based on Computational Thinking and Unplugged Computing. The methodology aims to teach and also welcome, since uncertainty moments like that, bring emotional needs that can harm the learning process.
\end{abstract}

Resumo. Diante da evidente desigualdade de gênero, principalmente nas áreas relacionadas à tecnologia, o projeto Código X busca proporcionar a meninas, que cursaram o ensino fundamental e vivem em regiões de vulnerabilidade social, um contato com atividades fora de sua realidade. Durante o período de isolamento social, novos desafios surgem para minimizar as desigualdades, estimulando o desenvolvimento de novas metodologias. Assim nasceu o Código $X$ em casa, criando uma forma de ensino à distância de lógica e programação. A metodologia é baseada em Pensamento Computacional e Computação Desplugada e visa ensinar e também acolher, visto que momentos de incerteza como esse, trazem necessidades emocionais que podem prejudicar o processo de aprendizagem.

\section{Introdução}

O avanço da tecnologia tem impactado de muitas formas todo o mundo. Os indivíduos devem estar aptos não só a utilizar as novidades tecnológicas, mas também a desenvolver soluções para tais [Medeiros et al. ]. O mercado de trabalho nesta área de desenvolvimento está em constante ascensão e não consegue preencher as vagas de trabalho geradas para suprir as demandas pelas tecnologias atuais, pois exige dos candidatos e candidatas 
habilidades muito específicas. Ainda assim, mesmo com o mercado aquecido, no que tange à participação feminina na área, apenas $17 \%$ dos programadores de Tecnologia da Informação (TI) no Brasil são mulheres, segundo dados da Serasa Experian e da ONU Mulheres ${ }^{1}$.

Além da desigualdade de gênero, existe grande desigualdade entre as próprias mulheres. Um exemplo disso é a disparidade ao acesso a computadores e internet por domicílios chefiados por mulheres brancas em comparação ao de chefiado por mulheres negras, que pode ser analisado no livro "Dossiê mulheres negras: retrato das condições de vida das mulheres negras no Brasil"[Marcondes et al. 2013]. Essa discrepância do acesso a bens e a exclusão digital reflete as desigualdades sociais, na perspectiva racial, que dificultam ainda mais a inserção da mulher negra na tecnologia.

Estudos sugerem que essas desigualdades no mercado de trabalho são reflexo de percepções naturalizadas na infância em relação a disciplinas de exatas [Jacobs 1991, Herbert and Stipek 2005, Jacobs and Eccles 1985, Dickhauser and Meyer 2006]. Como exemplo, [Rodríguez et al. 2020] realiza um estudo com quase 900 alunos e alunas do ensino fundamental (metade de cada sexo) e mostra que, embora não haja diferenças significativas entre os sexos no desempenho acadêmico, os grupos se diferem quando se trata da relação com a matemática. O estudo avalia o efeito das emoções no desempenho em matemática. Como resultado, perceberam que a ansiedade em relação à disciplina tem efeito maior nas meninas. Em outras palavras, o alto nível de ansiedade em relação à matemática faz com que as meninas tenham menos confiança em suas habilidades, impactando nas escolhas que fazem ao longo da vida.

No contexto em que vivemos, percebe-se a importância de ter conhecimento sobre as novas tecnologias, em destaque ter aptidão para a programação, habilidade que requer Pensamento Computacional. Este pensamento envolve a resolução de problemas baseando-se nos conceitos da Ciência da Computação, sendo fundamental para diversas áreas do conhecimento [Wing 2006]. Entretanto, desenvolvê-lo pode não ser simples para quem nunca teve contato com a área, sendo essencial o incentivo desde a formação básica do indivíduo. Nesse caso, é necessário o uso de estratégias relacionadas ao cotidiano de forma mais lúdica e adequada aos envolvidos, de forma a facilitar a aprendizagem [Medeiros et al. ].

Um método que existe com o objetivo de facilitar essa aprendizagem, principalmente na infância, é a Computação Desplugada [Bell et al. ]. A Computação Desplugada tem como objetivo disseminar os conhecimentos sobre as Ciências da Computação sem o uso de computadores ou qualquer meio digital [do Santos et al. 2016]. Essa metodologia incentiva a aprendizagem por meio da resolução de problemas, vivenciando o assunto. As técnicas utilizadas permitem o ensino de conceitos introdutórios à programação e de raciocínio lógico, além de algoritmos, de forma lúdica e interativa.

Em [Ferreira et al. , Werlich et al. , de Souza and Lopes ] são mostradas algumas iniciativas de aprendizagem de raciocínio lógico realizadas com alunos do Ensino Básico, Fundamental e Médio e preparação de alunos para competição na OBI (Olimpíada Brasileira de Informática) nas escolas. Os autores integram o Pensamento Computacio-

\footnotetext{
${ }^{1}$ https://epocanegocios.globo.com/Economia/noticia/2018/02/apenas-17-dos-programadoresbrasileiros-sao-mulheres.html
} 
nal, Computação Desplugada e metodologias ativas a conteúdos curriculares, no desenvolvimento do pensamento crítico e raciocínio lógico. Já os relatos apresentados em [Marquiori et al. , Passos et al. , de Pontes et al. ] tratam especificamente de trabalhos feitos com meninas. Estes trabalhos têm objetivos semelhantes aos apresentados aqui, uma vez que atuam no sentido de diminuir a lacuna existente entre a participação masculina e feminina no mundo da tecnologia.

Os desafios enfrentados são diversos, os que são mais comuns envolvem: a falta de perspectiva de continuidade dos estudos, os baixos recursos das escolas e comunidades nas quais estas meninas estão inseridas e falta de iniciativas das próprias escolas (ou redes) para apoiar os estudos por parte dos alunos na área de computação. Daí a necessidade, além de atuar no preenchimento das lacunas, é também, fazer com que essas intervenções sejam inclusivas o suficiente a fim de envolver as meninas no processo.

Na Figura 1, é mostrado um exemplo de utilização da Computação Desplugada em sala de aula, utilizando como referência o estudo de caso apresentado aqui. Nesta atividade foi utilizado um exercício simples, baseado no ato de se maquiar, para introduzir o conceito de instruções. A turma é dividida em grupos e cada grupo recebe o desenho de uma maquiagem pronta (esquerda). Cada grupo precisa descrever o passo a passo necessário, com os devidos materiais, para que uma pessoa que não viu o desenho possa reproduzi-lo em si (direita). Dessa forma, a dinâmica reproduz o funcionamento de um computador diante de uma rotina de programação. Atividades com esta característica são utilizadas pelo projeto social Código X para ensinar programação para meninas.

O projeto Código X: O Despertar Feminino para a tecnologia atua em uma escola municipal localizada em um bairro periférico da cidade de Ouro Preto, em Minas Gerais. O projeto tem como objetivo principal ensinar atividades práticas de caráter lógico para meninas em idade escolar. Para além do ensino, tem-se como meta estimular o empoderamento feminino ${ }^{2}$ e despertá-las para a prática de programação, utilizando a Computação Desplugada e a Programação em Blocos [Bau et al. 2017].

Em março do ano de 2020 foi decretada pela Organização Mundial da Saúde (OMS) a pandemia de uma nova doença: a COVID-19, havendo assim necessidade de isolamento social [WHO 2020] como combate à disseminação rápida desta. Deste modo, as aulas presenciais do Código $\mathrm{X}$ foram suspensas e todas as oficinas e atividades presenciais planejadas para o ano tiveram que ser adiadas.

Diante de todo o impacto causado pela necessidade urgente de distanciamento social, foi necessário pensar em uma solução que, além de garantir a continuidade das ações do projeto, pudesse acolher e ajudar as participantes a lidar melhor com a situação vivenciada. Além disso, estratégias utilizadas em outros contextos, como aulas online e vídeo chamadas não eram uma opção, já que a maioria das alunas não possuem os recursos necessários para tal. Eram necessárias soluções que garantissem a continuidade das atividades de forma acolhedora, que é um dos principais objetivos do projeto, mas com recursos que fossem viáveis para o momento.

Assim, surgiu o Código $\mathrm{X}$ em Casa, uma ação temporária do Código $\mathrm{X}$, que propõe o ensino remoto de lógica e programação à meninas em situação de vulnerabi-

\footnotetext{
2“A concessão de poder de participação social às mulheres, garantindo que estejam cientes acerca da luta pelos seus direitos, incluindo a igualdade entre gêneros". [de Oliveira and de Freitas 2017]
} 


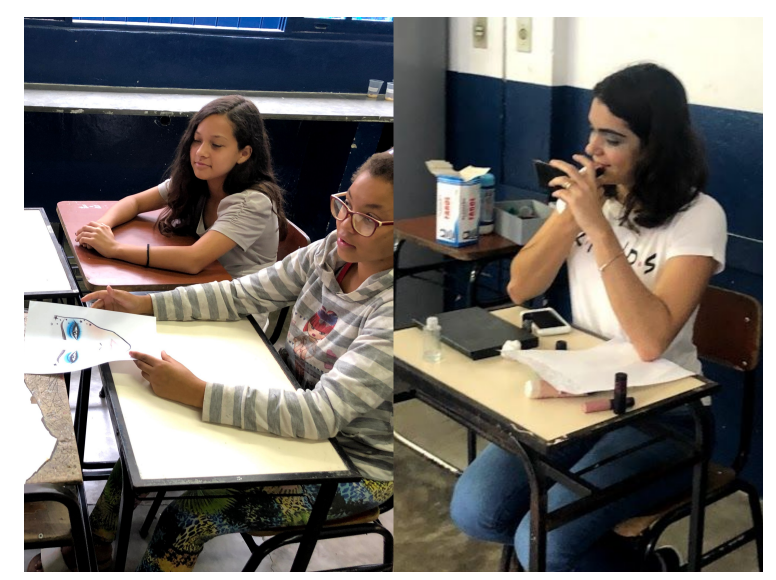

Figura 1. Aula com uso de metodologia desplugada

lidade social utilizando conceitos de Pensamento Computacional e Computação Desplugada, enquanto possibilita o acolhimento emocional às participantes. O objetivo deste trabalho é, portanto, apresentar a motivação, as soluções propostas, a organização e metodologia do Código X em casa, uma ação realizada pelo projeto social Código X.

\section{Métodos}

O Código X em Casa surgiu como uma ação que integra Pensamento Computacional e Computação Desplugada para oferecer a todas as alunas do Código X o acesso ao ensino de programação. Essa ação visa manter o contato e o interesse das meninas pela área de TI, em substituição às atividades presenciais. Nas subseções seguintes serão descritas a estrutura do projeto social Código X e o funcionamento do Código X em Casa.

\subsection{Estrutura do projeto social Código $X$}

A estrutura organizacional do Código X é dividida basicamente em dois grupos de voluntariado, chamados de Mentoras e Apoiadores. O grupo de mentoras é formado exclusivamente por mulheres, das mais variadas áreas de conhecimento, que são responsáveis diretamente pelas ações do projeto. Como pode ser visto na Figura 2, as mentoras são divididas em setores (Marketing, Infraestrutura, Metodologia, Estratégia, Financeiro e Comercial) e as que têm conhecimentos em programação participam ainda do grupo de Mentoria Técnica. Todas as aulas e oficinas realizadas pelo Código X devem ser acompanhadas por pelo menos uma dessas mentoras técnicas.

Os Apoiadores são pessoas, tanto homens quanto mulheres, que acreditam no projeto e desejam colaborar de outras formas, sem necessariamente assumir uma atividade em algum setor. Após a realização do cadastro, são convidados, sempre que necessário, a participar de ações esporádicas relacionadas ao projeto, seja disponibilizando algum serviço, ajudando na divulgação de ações ou contribuindo financeiramente.

\subsection{Ação Código $X$ em Casa}

O Código X em Casa foi desenvolvido a partir da necessidade de se continuar executando as atividades iniciadas pelo Código $\mathrm{X}$, que por hora, tiveram que ser adiadas. Com o desenvolvimento do Código X em Casa, as atividades do projeto puderam continuar, porém, de forma adaptada ao atual contexto. 


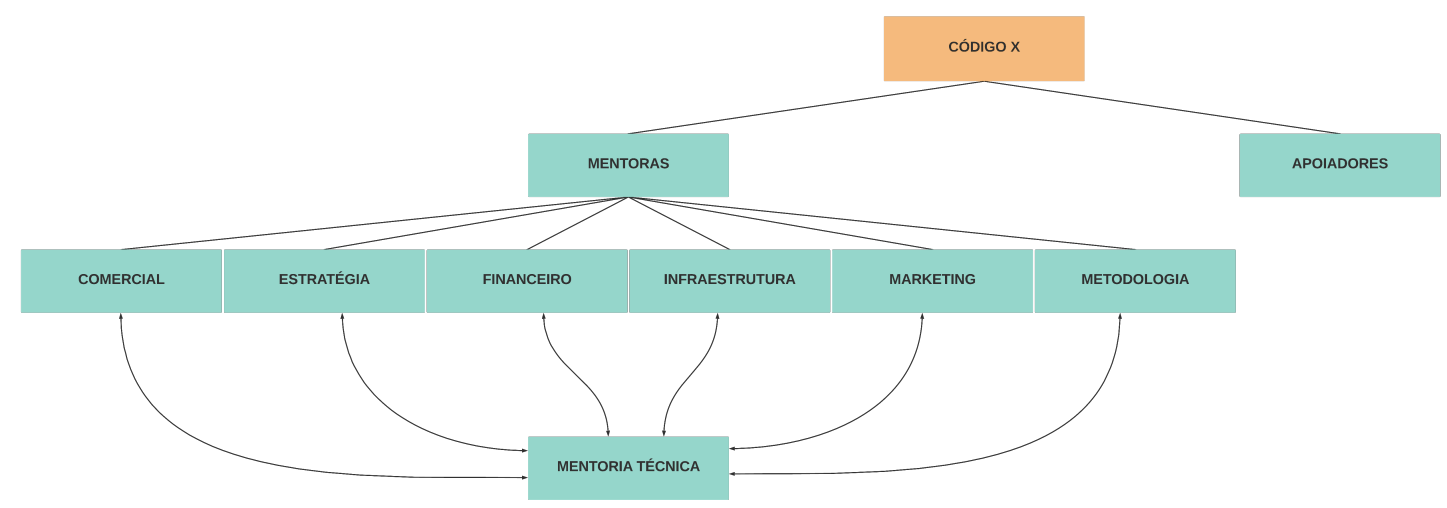

Figura 2. Estrutura Organizacional do Código X

As atividades do Código X em Casa tiveram início em maio de 2020 e estão sendo desenvolvidas a partir de reuniões semanais das mentoras responsáveis pelo setor de Metodologia. Nessas reuniões são definidas as estruturas das ações, tais como as atividades e os temas que serão propostos. É nesse momento que são decididas como serão realizadas as abordagens técnicas e relativas ao empoderamento feminino. Os outros setores são então envolvidos na operacionalização, divulgação, planejamento financeiro e coleta de doações.

A proposta implementada tem como objetivo viabilizar o contato das meninas com os temas relativos à lógica de programação, pensamento analítico, criatividade, e resolução de problemas, sem utilização de meios tecnológicos, assim como criar um espaço de acolhimento e de escuta. Pensando nisso, três ferramentas principais foram estruturadas: as Revistas Didáticas do Código X, o Clube da Leitura e o Programa de Amadrinhamento.

O fluxo de utilização dessas ferramentas é mostrado na Figura 3. Em resumo, as Revistas Didáticas (1) são produzidas e encaminhadas às alunas (2). O Programa de Amadrinhamento (3) permite a comunicação entre a equipe de produção e as alunas. Essa comunicação coleta feedbacks (5), utilizados como ferramenta para produção dos próximos conteúdos, e provê suporte às dúvidas. Ainda nos contatos feitos através do Programa de Amadrinhamento as alunas expõem suas preferências de leitura (4) e podem enviar recados para o grupo ou para uma colega específica (5). Através do levantamento destas informações, livros, jogos e revistas são enviadas a cada uma periodicamente. As estratégias utilizadas nesse processo são descritas nas subseções seguintes.

\subsection{Revistas Didáticas do Código $X$}

As Revistas Didáticas do Código X são seleções de exercícios adaptados de modo a introduzir e estimular o pensamento lógico e computacional, em uma linguagem juvenil, divertida e ilustrada, com o intuito de criar aproximação com as meninas. O planejamento das Revistas Didáticas é fundamentado para a distribuição de conteúdos introdutórios sobre o desenvolvimento de algoritmos, seguindo uma ordem crescente de complexidade. Destacam-se neste ponto os seguintes assuntos abordados sobre os algoritmos: sequenciamento de instruções, reconhecimento de padrões, estruturas de repetição, estruturas condicionais, funções e parâmetros. 


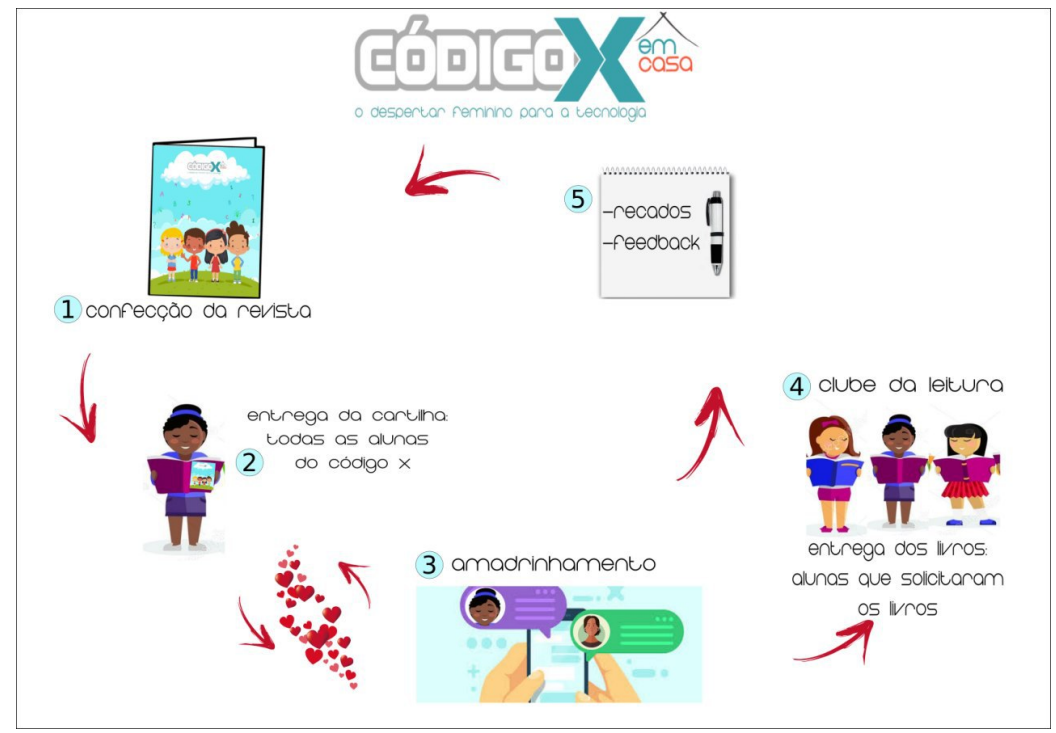

Figura 3. Fluxograma de funcionamento do Código X em Casa

Geralmente, exercícios disponibilizados por projetos como o Code.org e blockly.games ${ }^{3}$ são adaptados de modo que possam ser realizados apenas com lápis, tesoura e papel, sem perder a essência do pensamento computacional. Um exemplo da adaptação desses exercícios é o jogo Angry Birds, que pode ser visto na Figura 4. Todas as edições são complementadas com exercícios que estimulam o raciocínio lógico, matemático e criativo, além de mencionar assuntos interdisciplinares e de conhecimento geral.

\section{Angry Birds}

A sobrevivência dos Angry Birds está em risco. Vamos ajudá-los a lutar contra os porcos que roubaram seus ovos. Para isso associe a primeira coluna à segunda, ligando cada bloco de comandos às ações correspondentes que o Angry Bird do desenho deve executar para andar por um labirinto e chegar até o porco malvado que roubou seus ovos.Vamos pegar os porcos!

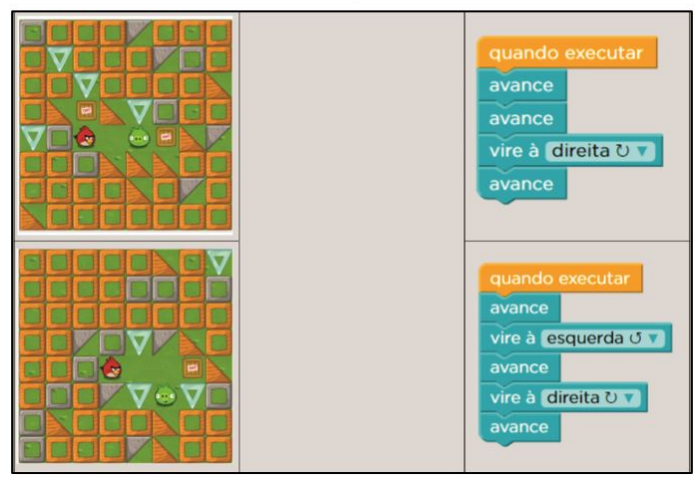

Figura 4. Adaptação desplugada do Angry Birds.

As atividades são pensadas cuidadosamente para se adaptarem à idade das alunas, que variam de 10 a 16 anos, de modo a desafiá-las sem causar desânimo quanto à dificuldade. Para isso, além de atividades que carecem da escrita, elas são convidadas a brincar, colorir, cortar e colar, criando soluções dinâmicas e divertidas.

\footnotetext{
${ }^{3}$ https://code.org/ —https://blockly.games
} 
Ainda nas revistas, são trazidas duas seções de intervenções que ocorrem paralelamente dentro do Código X em Casa. São elas: o Correio X e a Estante do Código X. O Correio $\mathrm{X}$ foi pensado como um convite à interação das alunas com o material produzido e como forma de conexão, tanto entre elas, quanto para com as mentoras do projeto. Nele as alunas escrevem recados que podem ser publicados nessa seção ou até mesmo enviados como cartas para suas amigas. Na Estante do Código X, pertencente ao Clube da Leitura, os títulos disponíveis para envio são apresentados às meninas para que possam escolher quais desejam ler.

As edições são disponibilizadas publicamente na internet para download ${ }^{4}$ e enviadas mensalmente por delivery para as alunas do projeto através de um motoboy, que segue rigorosamente as recomendações da OMS. O gabarito contendo as soluções é apresentado na edição seguinte, sanando possíveis dúvidas. As dúvidas também podem ser sanadas durante os contatos feitos através do Programa de Amadrinhamento.

\subsection{Programa de Amadrinhamento}

O Programa de Amadrinhamento é a ferramenta que integra os setores de produção do material aos feedbacks das meninas, como mostra o fluxograma da Figura 3. Baseado em um sistema de tele-acompanhamento, reuniu-se uma equipe de mulheres, mentoras e apoiadoras do Código X, que são chamadas de madrinhas. A criação dessa equipe tem $\mathrm{o}$ intuito de estabelecer um atendimento individualizado e personalizado via telefone ou Whatsapp durante a execução da ação. Cada uma delas é responsável pelo acompanhamento de uma ou mais meninas vinculadas ao projeto, tornando-as suas afilhadas.

As madrinhas são incentivadas a fazer contatos quinzenais com suas afilhadas para coletarem dúvidas e buscarem informações acerca do andamento e adesão às atividades propostas. A cada ligação, as madrinhas preenchem um formulário com as opiniões e sugestões das suas afilhadas sobre o trabalho realizado até o momento; selecionam os livros escolhidos na Estante do Código X para que sejam enviados nas semanas posteriores; e registram os recados para serem publicados ou enviados pelo Correio X. Os contatos ocorrem de forma acolhedora, aproximando as meninas ainda mais do Código X.

\subsection{Clube da leitura}

De modo alternado ao envio das cartilhas, o Clube da Leitura também se propõe a acontecer mensalmente, enviando livros, jogos e brinquedos adquiridos através de doações locais, à escolha das alunas. A finalidade da proposta é levar conhecimento de forma leve, estimulando o desenvolvimento pessoal e o hábito da leitura.

Os livros são recebidos através de doações, catalogados e os títulos disponíveis são descritos em uma seção da Revista Didática, chamada de Estante X. A cada ligação feita pelas madrinhas, as afilhadas podem sinalizar quais livros desejam receber e, ao término da leitura, avisam para que ele seja recolhido na próxima visita, deixando-o disponível novamente.

\section{Resultados e Discussão}

O relato apresentado aqui consiste em uma ação social considerada de grande relevância. Oportunizar acesso a um conhecimento que parece tão distante para as 23 meninas atendidas pelo projeto, com idades entre 10 e 16 anos, é algo que acaba por trazer inúmeras

\footnotetext{
${ }^{4}$ https://linktr.ee/codigox.ong
} 
questões à tona. Essas são postas aqui como resultados que foram observados e que são válidos tanto para as alunas quanto para todas e todos os voluntários envolvidos nas ações. Alguns cabem somente às meninas, outros cabem a todas e todos.

Para pensar nestes resultados, é preciso pensar na ação Código X em Casa como um ciclo, que inicia-se com a construção coletiva da Revista Didática e tem retroalimentação com as informações obtidas pelas madrinhas, o que permite que a abordagem proposta seja lapidada de acordo com as demandas que as meninas possuem. No meio do processo, também é possibilitado que as meninas tenham acesso e desenvolvam o gosto pela leitura. Este já é um primeiro resultado bastante interessante, pois a ação foca em atender às demandas delas.

Há também um processo de acolhimento no decorrer do fluxo, importante neste tempo de distanciamento social. A educação de fato passa pelo acolhimento, ferramenta perdida no momento em que não há mais a possibilidade de se reunir e conversar pessoalmente. Uma vez que é possível conversar com as madrinhas, as meninas sentem-se confortáveis para falar sobre as dificuldades das atividades, sobre o gosto (ou não) pela leitura, sobre o que sentem quando recebem as atividades e/ou livros em casa, dentre diversos assuntos. Os relatos das madrinhas, quando conversam com as meninas, refletem esse sentimento, como pode ser observado:

- Relato 1: "A conversa foi super saudável, descontraída e deu pra perceber que ela ficou muito feliz com o contato. Combinamos de ela me mandar qualquer dúvida que tiver pelo Whatsapp e ela está super empolgada com os livros e materiais que irá receber."

- Relato 2: "Amouuu. Me mandou mensagem contando a história e tudo o mais. Está super empolgada. Ainda não terminou de ler (o livro) porque ele é um pouco grande."

- Relato 3: "Ela está muito feliz com o Código X em Casa. Acredito que esteja fazendo bastante diferença na vida dela."

- Relato 4: "Achou muito legal. Tá adorando ter algo pra distrair quando não está cuidando dos irmãos. Além disso, adora ler e não vê a hora de receber os livros."

Neste sentido, entende-se que não somente as meninas estão sendo observadas e acolhidas. Ao envolver todas as voluntárias nos diversos processos, o Código X em Casa acaba por manter a ligação e diminuir o distanciamento entre todas as participantes do projeto Código X.

Algumas dificuldades foram encontradas ao longo do processo e outras certamente virão. Uma delas é a comunicação com algumas meninas, uma vez que nem todas têm acesso a telefone com aplicativo de mensagens. Neste caso, o contato é feito por intermédio dos pais. Outra dificuldade foi em relação ao processo de envio do material sem colocar em risco a saúde de cada uma das pessoas envolvidas. Um motoboy foi contratado e utiliza máscaras para levar o que for necessário, os materiais são embalados individualmente e todo o processo segue um fluxo bastante restrito.

O enfrentamento e disposição para solucionar todas as dificuldades que ora se apresentam é também um resultado que pode ser apresentado neste relato. A cada semana, durante as reuniões, todas as questões que envolvem a execução do Código X em Casa são discutidas em conjunto, analisadas e as ações para resolvê-las são estabelecidas. Dessa 
IX Congresso Brasileiro de Informática na Educação (CBIE 2020)

Anais do XXVI Workshop de Informática na Escola (WIE 2020)

forma é possível lapidar o material e ajustar as ações conforme a necessidade demandada pelo público alvo.

\section{Conclusão}

Apesar das inúmeras pesquisas realizadas comprovando a grande desigualdade social e de gênero no Brasil, vivenciar essas realidades na prática é ainda mais desafiador. Apenas a partir de um contato próximo é possível entender e buscar alterar os tristes cenários de desigualdade que nos rodeiam. Essa é a intenção do Código X, que não só propõe, como implementa ações, atualmente em uma escola municipal de região periférica em Ouro Preto, Minas Gerais.

Em um momento difícil para toda a sociedade, durante uma pandemia repleta de incertezas, a equipe do Código X percebeu que era necessário intervir na vida das alunas de forma acolhedora, criando alternativas que possibilitam não só o processo de ensino-aprendizagem mas algum amparo, conforto e refúgio às meninas. As Revistas Didáticas, assim como o Clube da Leitura, são ferramentas de ensino de Computação Desplugada e de Pensamento Computacional mas, além disso, funcionam como instrumentos de disseminação de empoderamento feminino, de educação, de criatividade e de entretenimento.

Foram vários os obstáculos encontrados para a realização das ações descritas, mas para cada um deles novas soluções foram projetadas, incluindo uma metodologia inovadora para o ensino de capacidades lógicas e computacionais em um contexto complexo e conturbado. Os retornos recebidos são positivos e podem ser observados mediante ofeedback das alunas, mentoras e apoiadoras do projeto, que demonstram muita satisfação com as intervenções aplicadas. Essa experiência gerou um espaço de acolhimento e escuta entre madrinhas e alunas, que surgiu como uma forma de interação em meio à situação de isolamento social. Além disso, a experiência promove um crescimento dentro da equipe de mentoras que conduzem o projeto social.

Portanto, apesar dos desafios enfrentados, que já se encontravam presentes antes do isolamento social e se somaram a outros devido à pandemia, a ação desenvolvida pelo Código X, o Código X em Casa, vem elaborando e propondo formas de ensinar suas alunas e instigar seus interesses para áreas das Ciências Exatas. Neste sentido, é notável que os desafios presentes também contribuíram para o desenvolvimento de uma nova metodologia de ensino remoto de lógica e programação em situações de instabilidade e emergência, proporcionando grandes expectativas para novas ações.

\section{Referências}

Bau, D., Gray, J., Kelleher, C., Sheldon, J., and Turbak, F. (2017). Learnable programming: blocks and beyond. Communications of the ACM, 60(6):72-80.

Bell, T., Rosamond, F., and Casey, N. Computer science unplugged and related projects in math and computer science popularization.

de Oliveira, M. R. and de Freitas, C. C. (2017). Meninas da vila: uma perspectiva transdisciplinar do empoderamento feminino.

de Pontes, M. M. G., Silva, W. P., Dantas, V. F., and de Lima Costa, T. K. Desafios no incentivo de meninas para a área de computação. 
de Souza, J. S. and Lopes, A. S. B. Estimulando o pensamento computacional e o raciocínio lógico no ensino fundamental por meio da obi e computação desplugada.

Dickhauser, O. and Meyer, W. (2006). Gender differences in young children's math ability attributions. Psychology Science, 48(1):3.

do Santos, E. R., Soares, G., Dal Bianco, G., da Rocha Filho, J. B., and Lahm, R. A. (2016). Estímulo ao pensamento computacional a partir da computação desplugada: uma proposta para educação infantil. Revista Latinoamericana de Tecnologia Educativa.

Ferreira, A. C., Melhor, A., Barreto, J., de Paiva, L. F., and Matos, E. Experiência prática interdisciplinar do raciocínio computacional em atividades de computação desplugada na educação básica.

Herbert, J. and Stipek, D. (2005). The emergence of gender differences in children's perceptions of their academic competence. Journal of Applied Developmental Psychology, 26(3):276-295.

Jacobs, J. E. (1991). Influence of gender stereotypes on parent and child mathematics attitudes. Journal of Educational Psychology, 83(4):518.

Jacobs, J. E. and Eccles, J. S. (1985). Gender differences in math ability: The impact of media reports on parents. Educational researcher, 14(3):20-25.

Marcondes, M. M., Pinheiro, L., Queiroz, C., Querino, A. C., Valverde, D., França, D., Sotero, E. C., Rios, F., Romio, J. A. F., Carvalho, L. D. P. d., et al. (2013). Dossiê mulheres negras: retrato das condições de vida das mulheres negras no brasil.

Marquiori, V., Oliveira, M., and Nascimento, G. Letramento de meninas em programação através do pensamento computacional para compreensão de problemas.

Medeiros, S., Rabelo, H., Nunes, I., Garcia, T. C. M., Medeiros, F., de Souza Rabelo, D. S., and Medeiros, A. Ensino de algoritmos com poemas através do editor poesia (): Relato de experiência.

Passos, J., Huh, K., Cavalheiro, L., Gonçalves, Y., Eler, M. M., Cubero, J., and Peres, S. M. Abrindo mentes com a computação desplugada: uma experiência com meninas de oitavo e nono anos.

Rodríguez, S., Regueiro, B., Piñeiro, I., Estévez, I., and Valle, A. (2020). Gender differences in mathematics motivation: Differential effects on performance in primary education. Frontiers in psychology, 10:3050.

Werlich, C., Crema, C., Kemczinski, A., and Gasparini, I. Pensamento computacional no ensino fundamental i: um estudo de caso utilizando computação desplugada.
WHO (2020). World health organization. https: / / www . who. int/emergencies/diseases/novel-coronavirus-2019/ situation-reports. Accessed: 2020-07-01.

Wing, J. M. (2006). Computational thinking. Communications of the ACM, 49(3):33-35. 